\title{
Simulating modular rolling guides elastic properties
}

\author{
L. Ya. Gilovoi ${ }^{1}, A . V$. Isaev $^{1}, A . V . \mathrm{Krutov}^{1}$, and $V . V$. Molodtsov ${ }^{1 . *}$ \\ ${ }^{1}$ Moscow State University of Technology "STANKIN", Russia
}

\begin{abstract}
Due to high performance characteristics of the modular rolling guides, they are widely used in the contemporary $\mathrm{CNC}$ machine designs by major manufacturers. The wrong choice of the guide characteristics can result in excessive cost of guides or maintenance, as well as insufficient rigidity of the machine. Various methods of modular rolling guides elastic properties studying and machine tool structure deformation analysis are known. Most of them are analytical solutions in which the cartridge body and the rail are considered non-deformable. The purpose of this study is to develop a hybrid numerical-analytical model based on the FEM and analytical solution. This approach makes it possible to take into account the joint deformation of bodies (cartridge body, rail, etc.) and contact deformation of the balls and raceways of the guides. The study was carried out in SolidWorks Simulation application. The simulation results correlate with the experimental data well. The displacements of the cartridge have lower values than the values obtained using the FEM model. To evaluate the significance of the model nonlinearity and the possibility of its linearization, a series of calculations of the gear hobbing machine structure elements were performed. The hybrid numerical-analytical model created improves the adequacy of the simulation results.
\end{abstract}

Contact deformations of joints [1], including sliding and rolling guides [2, 3, 9, 10], make a significant contribution to the elastic deformations of the bearing systems of machine tools.

Modular rolling guides have a high reliability. This ensured their predominant use in contemporary machine designs, primarily with CNC. Major manufacturers (INA, TNK, SKF, KOYO, Schaeffler, BoschRexroth, Hiwin, etc.) have mastered the production of a wide range of rolling guides. Hence, the designer is faced with the task of choosing the right components to create the designed machine structure balanced in its technical characteristics [4]. Modular rolling guides have a number of interdependent performance characteristics, which are selected depending on the operating conditions. The performance characteristics are the amount of preload, the stiffness of the guide and its lifespan. The wrong choice of the guide characteristics can result in excessive cost of guides or maintenance, as well as insufficient rigidity of the machine, which reduces its performance.

For this reason, the study of the elastic properties of modular rolling guides and methods of taking into account the yielding of such guides when analyzing the deformations of the machine tool structure is an urgent problem, the analytical solution of

* Corresponding author: scholom@list.ru 
which, based on the Hertzian contact model, was considered in [1]. In this case, the cartridge body and the rail are considered non-deformable.

This paper in contrast, for example, to [11] presents a hybrid numerical-analytical model based on the FEM and analytical solution [1,3]. This approach makes it possible to take into account the joint deformation of bodies (cartridge body, rail, etc.) and contact deformation of the balls and raceways of the guides. The study was carried out in SolidWorks Simulation application.

The relationship between the loads acting on the cartridge and its elastic displacements without taking into consideration the flexibility of the body and the rail is established by the relations:

$$
\{F\}=[K(\{\delta\})]\{\delta\}
$$

where $\{\delta)=\left[\delta_{y} \delta_{z .} \varphi_{x .} \varphi_{y .} \varphi_{z}\right]^{T}$ - is vector of cartridge displacements caused by loads $\{F\}=\left[F_{y}, F_{x}, M_{x}, M_{y}, M_{z}\right]^{T}$,

$[K(\{\delta\})]=\sum_{j=1}^{m} \sum_{i=1}^{n}\left[A_{i j}\right]^{T}\left[K_{i j}\left(\left\{\left[A_{i j}\right]\{\delta\}\right\}\right)\right]\left[A_{i j}\right]-$ is cartridge stiffness matrix, in which

$K_{i j}\left(\left\{\left[A_{i j}\right]\{\delta\}\right\}\right)=\left[\begin{array}{ll}\frac{\partial F_{y}\left(\delta_{y}, \delta_{z}\right)}{\delta y} & \frac{\partial F_{y}\left(\delta_{y}, \delta_{z}\right)}{\delta z} \\ \frac{\partial F_{z}\left(\delta_{y,} \delta_{z}\right)}{\delta y} & \frac{\partial F_{z}\left(\delta_{y}, \delta_{z}\right)}{\delta z}\end{array}\right]$ - is rolling element stiffness matrix and $\left[A_{i j}\right]=\left[\begin{array}{ccccc}1 & 0 & -z_{i j} & 0 & x_{i j} \\ 0 & 1 & y_{i j} & -x_{i j} & 0\end{array}\right]$ - coordinate transformation matrix.

The finite element models of the rolling guides were developed using the specifications of on the design of the following cartridges: TNK SHS25LC2 with a separator, Schaeffler KG KWVE25B G3V1 and BoschRexroth R1651 42220 without a separator (see Fig. 1) [7, 8].
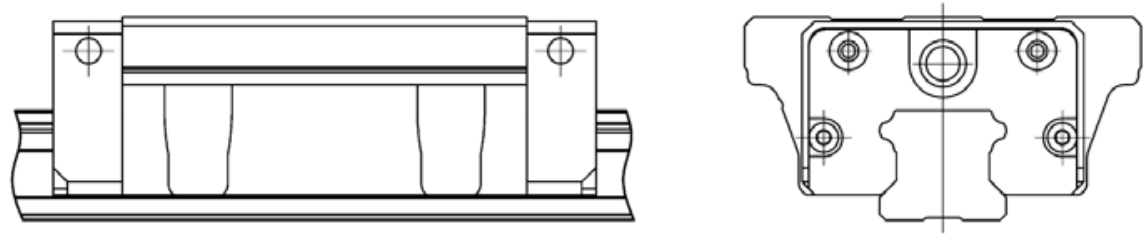

Fig 1. Cartridge geometry

In accordance with loading and displacements measuring diagrams shown in Figure 2, simulation modeling and a full-scale experiment on the stand were performed $[1,3]$. Simulated guides were selected based on the possibility of carrying out full-scale measurements.

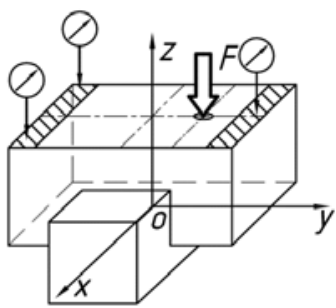

a)

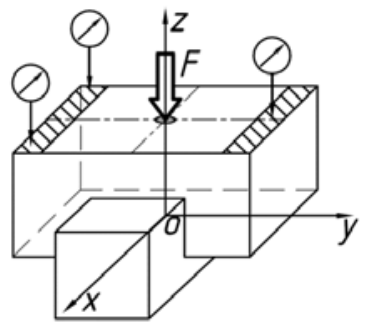

b)

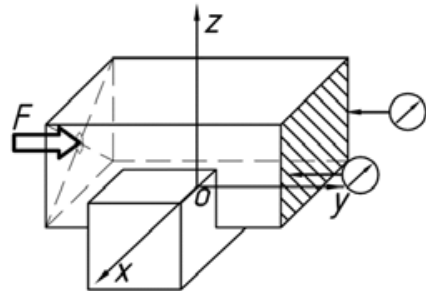

c)

Fig. 2. Location of displacement sensors and points of load application 
The hybrid simulation model which uses both the results of the analytical solution (1) and the possibilities of numerical analysis, is developed on the basis of two types of finite elements: volumetric tetrahedrons of the second order and virtual elastic elements of the "spring" type [5, 6]. The latter establish elastic bonds with stiffness (1) between the nodes of the finite element mesh along the designated surfaces. Such surfaces are cartridge and rail raceways. A simulation model for off-center application of force (Fig. 2, a), built considering the symmetry of the solution and simplification of the original geometry of the guide, is shown in Fig. 3. The model does not take into account the elastic properties of the parts attached to the cartridge. The rail-base connection is simulated by creating a tightening force at the places where the screws are installed and by friction at the joint between the rail and the base. The displacements are measured at inspection zones with subsequent calculation of average value for each zone.

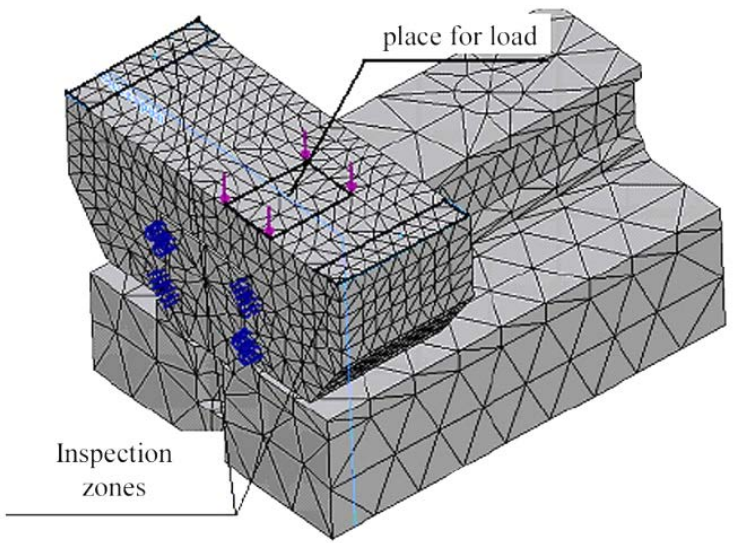

Fig. 3. Simulation model

The results of calculating the elastic displacements of the R1651 cartridge under the influence of preload and the combined action of preload and an eccentrically applied external vertical load are shown in Figures 4 a) and b), respectively. In Figure 4 b) arrows indicate the force created by the bolted rail-base connection.

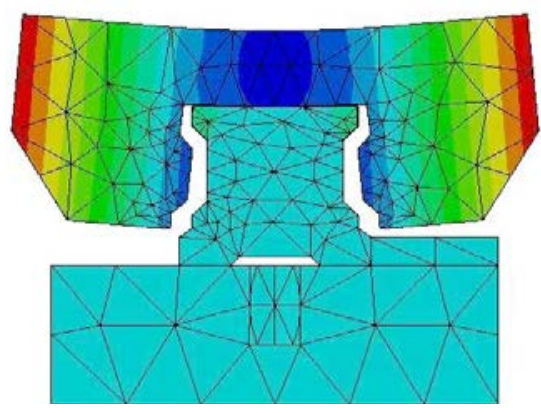

a)

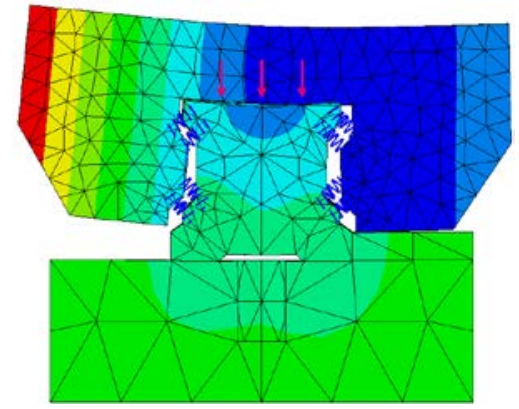

b)

Fig. 4. Deformation of the R1651 cartridge in the vertical direction under: a) - preload; b) - lateral load

As seen from Fig. 4, the preload corresponding to $10 \%$ of the cartridge's dynamic load capacity leads to a significant deflection of its body (about 17 microns). The most yielding is the middle part of the cartridge body. Its deformation can be reduced by choosing the correct design of the movable unit of the machine and following the installation instructions. 
The results of calculations performed on nonlinear solid and finite element models, as well as the data of full-scale experiments for the investigated guides are shown in Fig. 5 7: the data of full-scale experiments are plotted by dots, the results of FEM modeling are shown by the solid line, and the nonlinear solid modeling by the dashed line.

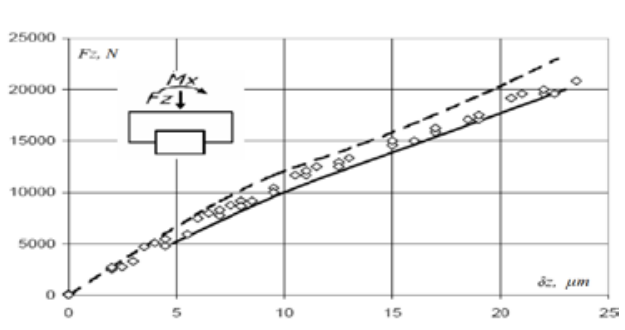

a)

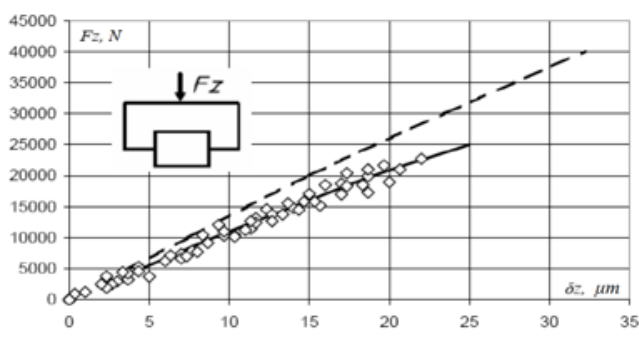

b)

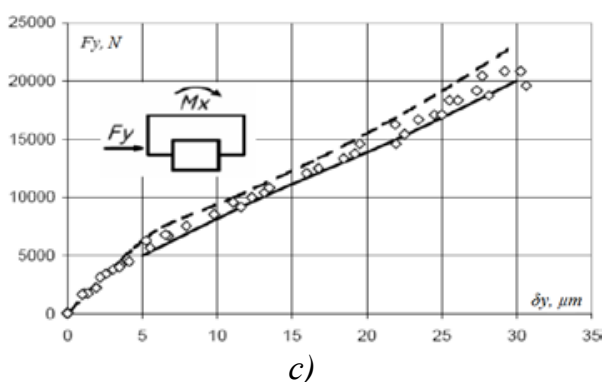

Fig. 5. Results of simulating and experimental data of the guide Rexroth 1651-419-20: a) $-\mathrm{Fz}+\mathrm{Mx}$; b) $-\mathrm{Fz} ; \mathrm{c})-\mathrm{Fy}+\mathrm{Mx}$

The simulation results correlate with the experimental data well. The displacements of the cartridge, calculated using the nonlinear solid model, have lower values than the values obtained using the FEM model. In other words, the nonlinear mathematical model shows greater rigidity than the FEM model. This is explained by the contribution made by the elastic deformations of the cartridge body and the rail.

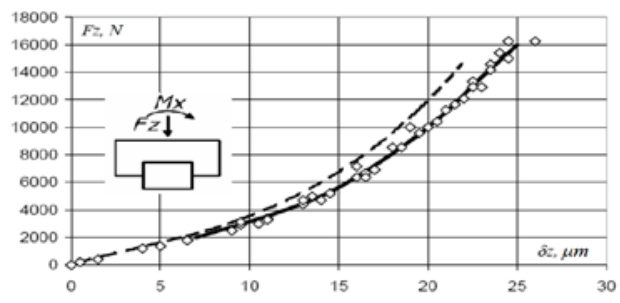

a)

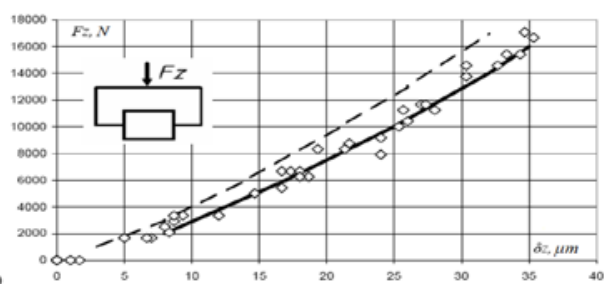

b)

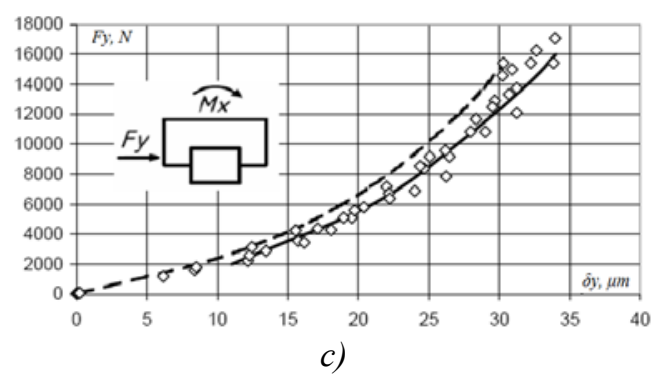

Fig. 6. Simulation results and experimental data of the INA KWVE25B guide: a) - Fz + Mx; b) - Fz; c) $-\mathrm{Fy}+\mathrm{Mx}$. 


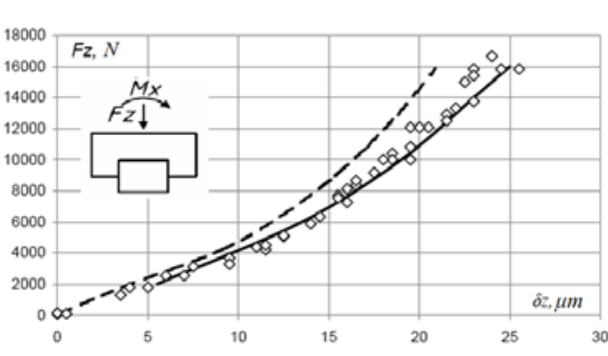

a)

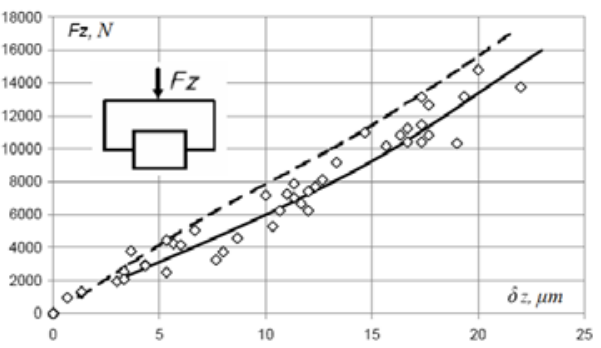

b)

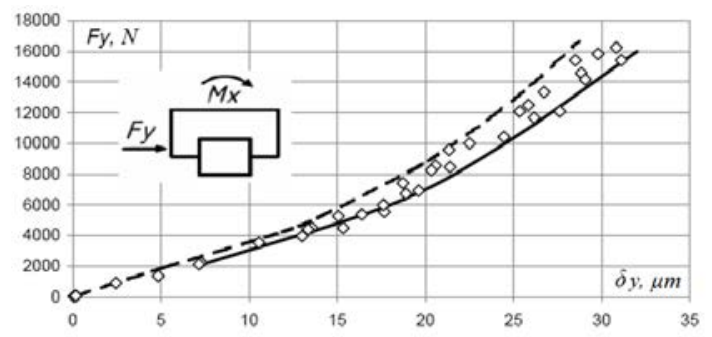

c)

Fig. 7. Results of modeling and experimental data of TNK SHS 25LC2: a) - Fz + Mx; b) - Fz; c) - Fy $+\mathrm{Mx}$.

The difference in displacements determined using two models grows with increasing load, since the deformations of the body and the rail, which are not taken into account in the analytical model, begin to affect more and more.

The maximum difference within the studied range of loads does not exceed $25 \%$, thus the contribution of contact deformations of bodies and raceways in the total deformation of the cartridge-rail system is at least $75 \%$. The rest is attributable to the deformations of the cartridge body and rail.

To evaluate the significance of the model nonlinearity and the possibility of its linearization, a series of calculations of the gear hobbing machine structure elements deformations [4] (see Fig. 8), subjected to dead weight loading and cutting forces, were performed.

The nonlinear elastic properties of the joints between the rolling elements and the raceways were taken into account by iterative application of the load and recalculation of the spring stiffness depending on the cartridge rolling elements displacement at each iteration. 


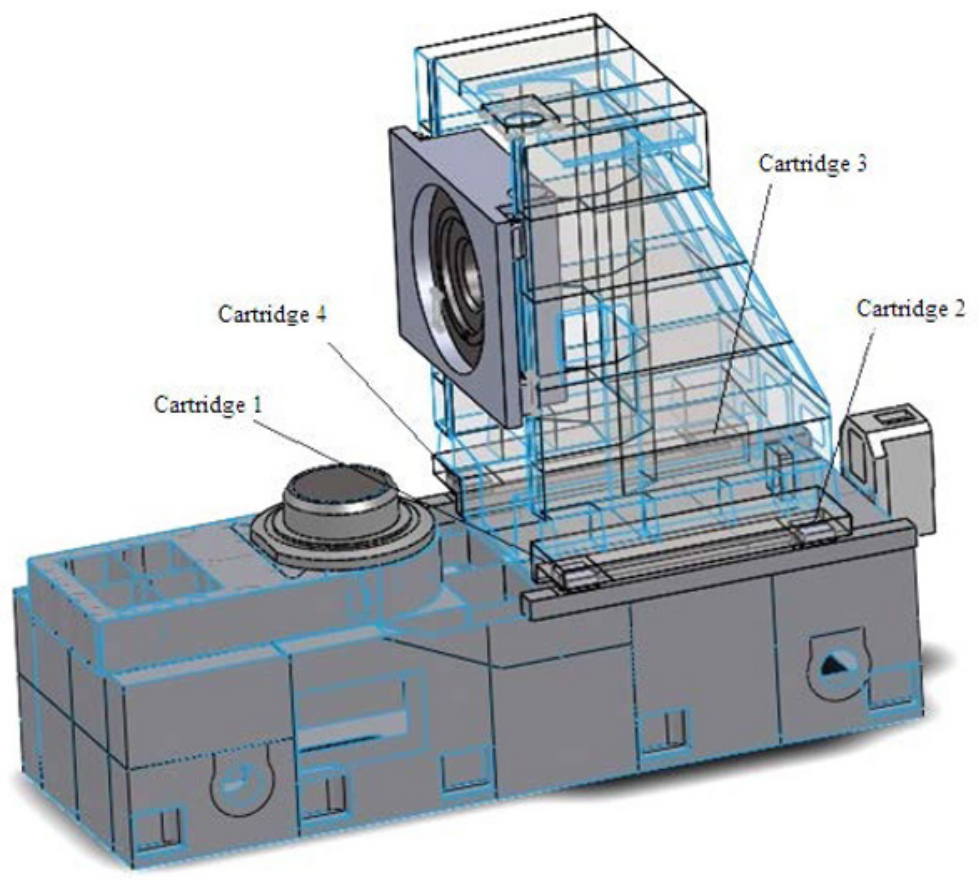

Fig. 8. Fragment of the machine structure: bed, column, guides.

Simulation results: stiffness and reaction on the cartridge raceways per iterations are shown in Table 1.

Table 1. Simulation results.

\begin{tabular}{|c|c|c|c|c|c|c|}
\hline \multirow{2}{*}{$\begin{array}{c}\text { Cartridge } \\
\text { No. }\end{array}$} & \multicolumn{7}{|c|}{ Iteration No.1 } & \multicolumn{2}{c|}{ Cartridge reaction, N } \\
\cline { 2 - 7 } & Raceway 1 & Raceway 2 & Raceway 3 & Raceway 4 & Ry & Rz \\
\hline 1 & 4,07 & 4,07 & 4,07 & 4,07 & $-3314,3$ & 7613 \\
\hline 2 & 4,07 & 4,07 & 4,07 & 4,07 & 2511,2 & 2219,7 \\
\hline 3 & 4,07 & 4,07 & 4,07 & 4,07 & 513,7 & 6716,2 \\
\hline 4 & 4,07 & 4,07 & 4,07 & 4,07 & $-4722,6$ & 9101,4 \\
\hline \multicolumn{7}{|c|}{ Iteration No.2 } \\
\hline 1 & 3,06 & 3,78 & 4,82 & 4,42 & -3264 & 7612,4 \\
\hline 2 & 4,10 & 3,68 & 4,06 & 4,41 & 2522,9 & 2235,5 \\
\hline 3 & 3,57 & 3,47 & 4,53 & 4,59 & 504,6 & 6702,5 \\
\hline 4 & 2,68 & 3,81 & 4,99 & 4,46 & $-4775,6$ & 9099,9 \\
\hline \multicolumn{7}{|c|}{ Iteration No.3 } \\
\hline 1 & 3,07 & 3,77 & 4,81 & 4,43 & $-3268,5$ & 7612,8 \\
\hline 2 & 4,10 & 3,68 & 4,06 & 4,41 & 2523,4 & 2234,8 \\
\hline 3 & 3,57 & 3,47 & 4,53 & 4,59 & 503,1 & 6703,5 \\
\hline 4 & 2,67 & 3,81 & 5,00 & 4,45 & -4770 & 9099,5 \\
\hline
\end{tabular}

The table shows that taking into account the nonlinearity gives a refinement of the reaction values by no more than $2 \%$. Thus, when carrying out engineering analysis of the machine tools structures, the change in the stiffness of cartridges under the external loads can be ignored. 


\section{Conclusions}

1. The use of the analytical solution of the Hertz contact problem and simulation model based on the finite element method made it possible to create a hybrid numerical-analytical model and to improve the adequacy of the simulation results.

2. In the general strain figure of the modular guide, the cartridge body deformation comprises about $25 \%$. Hence, the part mated with the cartridge shall have high stiffness.

3. Linearization of the simulation model of the rolling guides makes it possible to analyze the flexibility of the machine tools structures with an accuracy sufficient for engineering analysis (the error does not exceed $2 \%$ ).

\section{References}

1. A.V. Krutov, V.V. Molodtsov Simulation of modular guide systems. Russian Engineering Research. T. 31. №3. pp. 270-275 (2011).

2. V.V. Molodtsov. Raschet i konstruirovaniye napravlyayushchikh i privodov podachi stankov s CHPU: uchebnoye posobiye./ M.: ITS GOU MGTU «Stankin», 184 p. (2006).

3. A.V. Krutov, V.V. Molodtsov. Izmereniye uprugikh deformatsiy pretsizionnykh modul'nykh napravlyayushchikh kacheniya. Izmeritel'naya tekhnika. №5. pp. 49-51, (2012).

4. L.Ya. Gilovoy, V.V. Molodtsov Zubofrezernyye stanki povyshennoy zhestkosti. Vestnik MGTU Stankin. №2 (45) pp. 8-14. (2018).

5. A.N. Polyakov, S.V. Kamenev: A method to select the finite element models for the structural analysis of machine tools. Journal of Physics: Conference Series. International Scientific Conference "Conference on Applied Physics, Information Technologies and Engineering - APITECH-2019". Krasnoyarsk Science and Technology City Hall of the Russian Union of Scientific and Engineering Associations; Polytechnical Institute of Siberian Federal University. C. 44033 (2019).

6. A.N. Polyakov, A.I. Dodorov Vestnik, Metodika vybora tverdotel'nykh konechnykh elementov modeley nesushchikh sistem stankov pri provedenii ikh inzhenernogo analiza. Belgorodskogo gosudarstvennogo tekhnologicheskogo universiteta im. V.G. Shukhova . №6. pp 102-116. (2019).

7. THK. General catalog. TOKYO, JAPAN.THK.Co. LTD, (2006) 650p.

8. Schaeffler KG Linear Technology Division 66424 Homburg/Saar Germany, (2006), $34 \mathrm{p}$.

9. W. Sun, X. Kong, B. Wang and L. Xingzhan, Statics modeling and analysis of linear rolling guideway considering rolling balls contact, Journal of Mechanical Engineering Science, Vol. 229(I), pp 168-179 (2015).

10. P. Pawelko, S. Berczynski, Z. Gradziel, Modeling roller guides with preload. Archives of Civil and Mechanical Engineering, Volume 14, Issue 4, 5 pp 691-699, (August 2014).

11. A. Haukhorova, Yi Liang, Hutian Feng, Bin Xu Study of Stiffness of Linear Guide Pairs by Experiment and FEA. World Journal of Engineering and Technology Vol.4 №3D, (October 2016). 